\title{
Desmidiaceae, Gonatozygaceae e Mesotaeniaceae na comunidade perifítica do reservatório de Salto do Vau (Bacia do rio Iguaçu, PR)
}

\author{
Sirlene Aparecida Felisberto ${ }^{1}$ e Liliana Rodrigues ${ }^{2,3}$
}

Recebido: 18.10.2007; aceito: 30.05.2008

\begin{abstract}
Desmidiaceae, Gonatozygaceae and Mesotaeniaceae from the periphytic community in "Salto do Vau" Reservoir (Iguaçu river basin, Paraná State)). The aim of this work was to inventory the species of the families Desmidiaceae, Gonatozygaceae and Mesotaeniaceae from the periphytic community of a reservoir, located in south Brazil. The samples were collected during summer and winter in the distinct regions along the river-dam bed. The substrata collected, always in the littoral region, were petioles of aquatic vegetation. In the results 45 taxa were registered, belonging to the genera Actinotaenium (1 species), Cosmarium (17), Cylindrocystis (1), Euastrum (3), Gonatozygon (1), Hyalotheca (1), Micrasterias (7), Netrium (1), Pleurotaenium (1), Spondylosium (1), Staurastrum (9), and Staurodesmus (2). Higher species richness occurred in the transition region. Euastrum denticulatum Gay and Hyalotheca dissiliens (Smith) Brébisson ex Ralfs showed $100 \%$ of occurrence, while Cosmarium abbreviatum Raciborski var. minus (West \& West) Krieger \& Gerloff and Pleurotaenium ehrenbergii (Brébisson) De Bary occurred in 83\% of the samples.
\end{abstract}

Key words: longitudinal distribution, Periphytic algae, Zygnemaphyceae

RESUMO - (Desmidiaceae, Gonatozygaceae e Mesotaeniaceae na comunidade perifítica do reservatório de Salto do Vau (Bacia do rio Iguaçu, PR). Com este trabalho, objetivou-se investigar as espécies pertencentes às famílias Desmidiaceae, Gonatozygaceae e Mesotaeniaceae na comunidade perifítica de um reservatório, localizado no Sul do Brasil. As amostras foram coletadas durante os períodos de verão e inverno em distintas regiões ao longo do eixo rio-barragem do reservatório. Os substratos, coletados sempre na região litorânea, foram pecíolos de vegetação aquática. Foram identificados 45 táxons, distribuídos nos gêneros Actinotaenium (1 espécie), Cosmarium (17), Cylindrocystis (1), Euastrum (3), Gonatozygon (1), Hyalotheca (1), Micrasterias (7), Netrium (1), Pleurotaenium (1), Spondylosium (1), Staurastrum (9) e Staurodesmus (2). Maior riqueza de espécies ocorreu na região de transição para ambos os períodos de coleta. Euastrum denticulatum Gay e Hyalotheca dissiliens (Smith) Brébisson ex Ralfs apresentaram 100\% de ocorrência, enquanto Cosmarium abbreviatum Raciborski var. minus (West \& West) Krieger \& Gerloff e Pleurotaenium ehrenbergii (Brébisson) De Bary ocorreram em $83 \%$ das amostras.

Palavras-chave: algas perifíticas, distribuição longitudinal, Zygnemaphyceae

\section{Introdução}

As desmídias são algas verdes microscópicas, que ocorrem em todos os ambientes aquáticos e quase exclusivamente em água doce, compondo a parte maior da classe Zygnemaphyceae. A primeira notícia sobre a ocorrência de desmídias no território brasileiro está em Ehrenberg (1843). De acordo com Bicudo \& Menezes (2006) e Araújo \& Bicudo (2006) um dos gêneros mais antigos das Desmidiaceae e de todas as algas verdes é Cosmarium, com 1.500 espécies já descritas.

Características dos gêneros e espécies representam uma grande diversidade morfológica das células que fazem das desmídias organismos extraordinariamente fascinantes. Segundo Parra \& Bicudo (1995), as diferenças entre gêneros e espécies são baseadas na forma, ornamentação da membrana e estrutura das células vegetativas, examinadas de frente, de lado e de cima. Nas desmídias sacodermes, da família Mesotaeniaceae, os representantes são constituídos por células cilíndricas curtas, cujas paredes celulares não possuem poros e nem linha mediana, enquanto nas desmídias placodermes, da família Desmidiaceae, cada célula consiste em duas porções com uma parede celular muito mais complexa e perfurada por sistema de poros (Brook 1981). Até algum tempo atrás

1. Universidade Federal de Goiás, Campus Samambaia (Campus II), Prédio da Reitoria, Caixa Postal 131, 74001-970 Goiânia, GO, Brasil

2. Universidade Estadual de Maringá, Programa de Pós-graduação em Ecologia de Ambientes Aquáticos Continentais - PEA - NUPÉLIA, Bloco G-90, Av. Colombo 5790, 87020-900 Maringá, PR, Brasil

3. Autor para correspondência: lrodrigues@nupelia.uem.br 
os gêneros Gonatozygon e Genicularia estiveram subordinados à família das desmídias sacodermes (Mesotaeniaceae) por causa da parede celular com estrutura simples e modo de divisão; mas após estudos detalhados em microscopia eletrônica foi constatado que a parede celular ao contrário do que se pensava, é composta por um sistema delicado de poros, apresentando assim uma parede esculturada (Brook 1981). Assim, ambos os gêneros deveriam ser incluídos na família Closteriaceae (Bourrelly 1966) ou, como sugerido por Mix (1972), colocados em uma família separada, Gonatozygaceae (Brook 1981). Dados baseados em seqüências de $r b c \mathrm{~L}$ realizados por McCourt et al. (2000) suportam o sistema de classificação de Mix (1973) para o reconhecimento das famílias Closteriaceae, Gonatozygaceae, Peniaceae e Desmidiaceae das placodermes.

Com este trabalho objetivou-se o estudo taxonômico das espécies pertencentes às famílias Desmidiaceae, Gonatozygaceae e Mesotaeniaceae, provenientes de três regiões distintas do reservatório de Salto do Vau (Bacia do rio Iguaçu), ao longo de um gradiente longitudinal em dois períodos do ano (verão e inverno).

\section{Material e métodos}

O reservatório da Usina Hidrelétrica de Salto do

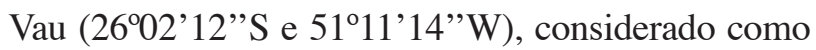
oligotrófico (Pagioro et al. 2005) localiza-se na margem esquerda do rio Palmital, município de União da Vitória, no Estado do Paraná, divisa com Porto União, Estado de Santa Catarina (figura 1). A usina foi inaugurada em 1959 e apresenta uma potência de 0,9 MW, com $8,2 \mathrm{~km}$ de extensão em seu reservatório. Seu substrato é composto por rochas sedimentares. A UHE de Salto do Vau foi construída numa região de vale, possuindo grande área de floresta nativa e preservada.

Para a amostragem qualitativa da comunidade de algas perifíticas foram realizadas duas coletas no ano de 2002, nos períodos de verão e inverno, nas regiões: superior, intermediária e lacustre do reservatório de Salto do Vau (bacia do rio Iguaçu).

Os substratos (pecíolos de vegetação aquática) foram coletados sempre na região litorânea de todos os pontos de coleta. Independentemente da espécie, a coleta de parte do vegetal sempre foi realizada em estágio adulto.

O perifíton coletado (epifíton) foi removido do substrato com lâmina de barbear e jatos de água destilada, transferido para frascos de $150 \mathrm{~mL}$, fixado e preservado com solução de Transeau. O estudo taxonômico das desmídias foi realizado pela análise de aproximadamente 13 lâminas temporárias ou até não mais serem registradas novas espécies. Esse procedimento, assim como as ilustrações, foram realizadas em microscópio binocular, acoplado com ocular micrometrada e câmara clara (marca Nikon), em objetivas de 40 e $100 \times$.

A identificação dos táxons foi baseada em literatura clássica (Růžička 1977, Prescott et al. 1981, Förster 1982, Croasdale \& Flint 1986), regionais e específicas. O enquadramento taxonômico adotado foi o proposto por Mix (1972). A organização das espécies dentro de cada família foi feita por ordem alfabética.

Para os gêneros com mais de uma espécie foi apresentada chave dicotômica para identificação dos táxons. As amostras que serviram de base para este trabalho estão depositadas no Herbário da Universidade Estadual de Maringá (HUEM) sob números de registro 11412 a 11417.

As medidas (em $\mu \mathrm{m}$ ) estão representadas pelos seguintes símbolos: compr. = comprimento; larg. = largura. As estações de coleta foram representadas pelos símbolos $\mathrm{S}=$ superior; $\mathrm{I}=$ intermediária e $\mathrm{L}=$ lacustre.

\section{Resultados e Discussão}

Foram identificados 45 táxons (tabela 1), distribuídos nos gêneros Actinotaenium (1), Cosmarium (17), Cylindrocystis (1), Euastrum (3), Gonatozygon (1), Hyalotheca (1), Micrasterias (7), Netrium (1), Pleurotaenium (1), Spondylosium (1), Staurastrum (9) e Staurodesmus (2).

Todos os 12 gêneros, identificados para o reservatório de Salto do Vau foram classificados como segue.

\section{MESOTAENIACEAE}

Cylindrocystis Menegh. ex De Bary

Cylindrocystis brebissonii Meneghini ex De Bary, Unt. Fam. Conjugat. 35, 7: 1. 1858.

Figura 2

Célula 3,4-5 vezes mais longa que larga, cilíndrica, com as extremidades arredondadas; parede celular lisa; cloroplasto com um pirenóide. Compr.:

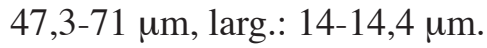


Tabela 1. Ocorrência dos táxons de Desmidiaceae, Gonatozygaceae e Mesotaeniaceae no reservatório de Salto do Vau, no ano de 2002. Regiões do reservatório: Superior (S), Intermediária (I) e Lacustre (L).

\begin{tabular}{|c|c|c|c|c|c|c|}
\hline \multirow{2}{*}{ Família/Espécies } & \multicolumn{3}{|c|}{ Verão } & \multicolumn{3}{|c|}{ Inverno } \\
\hline & $\mathrm{S}$ & I & $\mathrm{L}$ & $\mathrm{S}$ & I & $\mathrm{L}$ \\
\hline \multicolumn{7}{|l|}{ MESOTAENIACEAE } \\
\hline Cylindrocystis brebissonii & & & $\mathbf{X}$ & & $\mathbf{X}$ & \\
\hline Netrium digitus & & & $\mathbf{X}$ & & & \\
\hline \multicolumn{7}{|l|}{ GONATOZYGACEAE } \\
\hline Gonatozygon monotaenium & & $\mathbf{X}$ & $\mathbf{X}$ & $\mathbf{x}$ & $\mathbf{X}$ & \\
\hline \multicolumn{7}{|l|}{ DESMIDIACEAE } \\
\hline Actinotaenium globosum & & $\mathbf{x}$ & $\mathbf{X}$ & & & \\
\hline Cosmarium abbreviatum var. minus & $\mathbf{X}$ & $\mathbf{X}$ & $\mathbf{x}$ & $\mathbf{x}$ & $\mathbf{X}$ & \\
\hline C. amoenum var. constrictum & $\mathbf{X}$ & & $\mathbf{X}$ & & & \\
\hline C. bioculatum & & $\mathbf{X}$ & & & & \\
\hline C. comissurale var. crassum & & $\mathbf{X}$ & & & & \\
\hline C. contractum & & & $\mathbf{X}$ & & $\mathbf{X}$ & \\
\hline C. laeve & & $\mathbf{X}$ & $\mathbf{X}$ & $\mathbf{X}$ & & \\
\hline C. minimum var. rotundatum & & $\mathbf{X}$ & & & & \\
\hline C.pseudoconnatum & $\mathbf{X}$ & $\mathbf{X}$ & $\mathbf{X}$ & & & \\
\hline C.punctulatum & & $\mathbf{X}$ & $\mathbf{X}$ & & & $\mathbf{X}$ \\
\hline C. regnellii & & $\mathbf{x}$ & & $\mathbf{x}$ & & \\
\hline C. regnesii & & $\mathbf{X}$ & & & & \\
\hline C. reniforme & & $\mathbf{X}$ & & $\mathbf{x}$ & $\mathbf{X}$ & $\mathbf{x}$ \\
\hline C. subspeciosum & & $\mathbf{X}$ & $\mathbf{X}$ & $\mathbf{x}$ & & \\
\hline C. subspeciosum var. validius & & $\mathbf{X}$ & $\mathbf{x}$ & & $\mathbf{X}$ & \\
\hline C. subtumidum & & $\mathbf{X}$ & & & & \\
\hline C. vexatum & & $\mathbf{X}$ & $\mathbf{X}$ & & & $\mathbf{x}$ \\
\hline Cosmarium sp. & & & $\mathbf{X}$ & & & \\
\hline Euastrum denticulatum & $\mathbf{X}$ & $\mathbf{X}$ & $\mathbf{X}$ & $\mathbf{x}$ & $\mathbf{X}$ & $\mathbf{x}$ \\
\hline Euastrum gemmatum & & $\mathbf{X}$ & $\mathbf{X}$ & & & \\
\hline E. insulare & & $\mathbf{X}$ & & & & \\
\hline Hyalotheca dissiliens & $\mathbf{X}$ & $\mathbf{x}$ & $\mathbf{X}$ & $\mathbf{x}$ & $\mathbf{X}$ & $\mathbf{x}$ \\
\hline Micrasterias excavata var. excavata & & & $\mathbf{X}$ & & & \\
\hline M. laticeps var. laticeps & & & & $\mathbf{x}$ & $\mathbf{X}$ & \\
\hline Micrasterias mahabuleshwarensis & & & $\mathbf{X}$ & & & \\
\hline M. radiosa var. radiosa & & $\mathbf{X}$ & & & & \\
\hline M. radiosa var. elegantior & & & & & $\mathbf{x}$ & \\
\hline M. rotata & & & $\mathbf{X}$ & & $\mathbf{X}$ & \\
\hline M. truncata var. pusilla & & & $\mathbf{x}$ & & & \\
\hline Pleurotaenium ehrenbergii & $\mathbf{X}$ & $\mathbf{X}$ & $\mathbf{X}$ & $\mathbf{x}$ & $\mathbf{x}$ & \\
\hline Spondylosium planum & & & & & $\mathbf{x}$ & \\
\hline Staurastrum alternans & & $\mathbf{X}$ & & $\mathbf{x}$ & $\mathbf{x}$ & $\mathbf{X}$ \\
\hline S. claviferum & $\mathbf{X}$ & & & & $\mathbf{x}$ & \\
\hline S. disputatum & & $\mathbf{X}$ & & & & \\
\hline
\end{tabular}


Tabela 5 (continuação)

\begin{tabular}{|c|c|c|c|c|c|c|}
\hline \multirow{2}{*}{ Família/Espécies } & \multicolumn{3}{|c|}{ Verão } & \multicolumn{3}{|c|}{ Inverno } \\
\hline & $\mathrm{S}$ & I & $\mathrm{L}$ & $\mathrm{S}$ & $\mathrm{I}$ & $\mathrm{L}$ \\
\hline S. hantzschii & $\mathbf{x}$ & $\mathbf{X}$ & $\mathbf{X}$ & $\mathbf{X}$ & & \\
\hline S. margaritaceum & & & $\mathbf{X}$ & & $\mathbf{X}$ & \\
\hline S. orbiculare & & & & & $\mathbf{X}$ & \\
\hline S. orbiculare var. depressum & & $\mathbf{X}$ & $\mathbf{X}$ & & & \\
\hline S. setigerum & & $\mathbf{X}$ & $\mathbf{X}$ & & & \\
\hline S. trifidum var. inflexum & & $\mathbf{X}$ & & & & \\
\hline S. dejectus var. apiculatus & & & $\mathbf{X}$ & & & \\
\hline S. dickiei var. dickiei & & $\mathbf{X}$ & & $\mathbf{X}$ & $\mathbf{X}$ & $\mathbf{X}$ \\
\hline
\end{tabular}

Material examinado: BRASIL. PARAnÁ: União da Vitória, Reservatório de Salto do Vau, região lacustre, 2-IV-2002, S.A. Felisberto s.n. (HUM11414); idem, região intermediária, 6-IX-2002, S.A. Felisberto s.n. (HUM11416).

\section{Netrium (Nägeli) Itzigsohn \& Rothe}

Netrium digitus (Ehrenberg) Itzigsohn \& Rothe in Rabenhorst, Alg. Sachsen 508. 1856 = Closterium digitus Ehrenberg, Abh. Akad. Berlin: 68. 1832.

Figura 3

Célula 3,8 vezes mais longa que larga, elíptica, atenuando gradualmente até o ápice truncadoarredondado; margens laterais convexas; parede celular lisa; cloroplastos 2, axiais, com projeções longitudinais denticuladas, proeminentes. Compr.: 133-146 um, larg.: 35-38 $\mu \mathrm{m}$.

Material examinado: BRASIL. PARANá: União da Vitória, Reservatório de Salto do Vau, região lacustre, 2-IV-2002, S.A. Felisberto s.n. (HUM11414).

\section{GONATOZYGACEAE}

\section{Gonatozygon De Bary}

Gonatozygon monotaenium De Bary ex Rab., Alg. Sachsen: 539. 1856.

Figura 4

Célula 8,8-17 vezes mais longa que larga, cilíndrica, alongada; ápices levemente dilatados, truncados; ângulos apicais espessados, levemente arredondados; parede celular recoberta por grânulos até as extremidades; cloroplasto axial, 7-12 pirenóides. Compr.: 104-136 $\mu \mathrm{m}$, larg.: 7-12 $\mu \mathrm{m}$.

Material examinado: BRASIL. PARANá: União da Vitória, Reservatório de Salto do Vau, região intermediária, 2-IV-2002, S.A. Felisberto s.n. (HUM11413); idem, região lacustre, 2-IV-2002, S.A. Felisberto s.n. (HUM11414); idem, região superior, 6-IX-2002, S.A. Felisberto s.n. (HUM11415); idem, região intermediária, 6-IX-2002, S.A. Felisberto s.n. (HUM11416).

\section{DESMIDIACEAE}

Actinotaenium (Nägeli) Teiling

Actinotaenium globosum (Bulnh.) Förster, Amazoniana 2:43. 1969 三 Cosmarium globosum Bulheim, Hedwigia 2(9): 52. 1861.

Figura 5

Célula 1,6 vez mais longa que larga, cilíndrica; constrição mediana rasa; margens laterais com ápices arredondados; vista apical circular; parede celular pontuada; cloroplasto em cristas com um pirenóide por

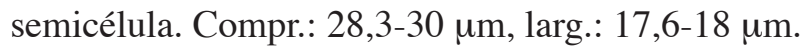

Material examinado: BRASIL. PARAnÁ: União da Vitória, Reservatório de Salto do Vau, região intermediária, 2-IV-2002, S.A. Felisberto s.n. (HUM11413); região lacustre, 2-IV-2002, S.A. Felisberto s.n. (HUM11414). 


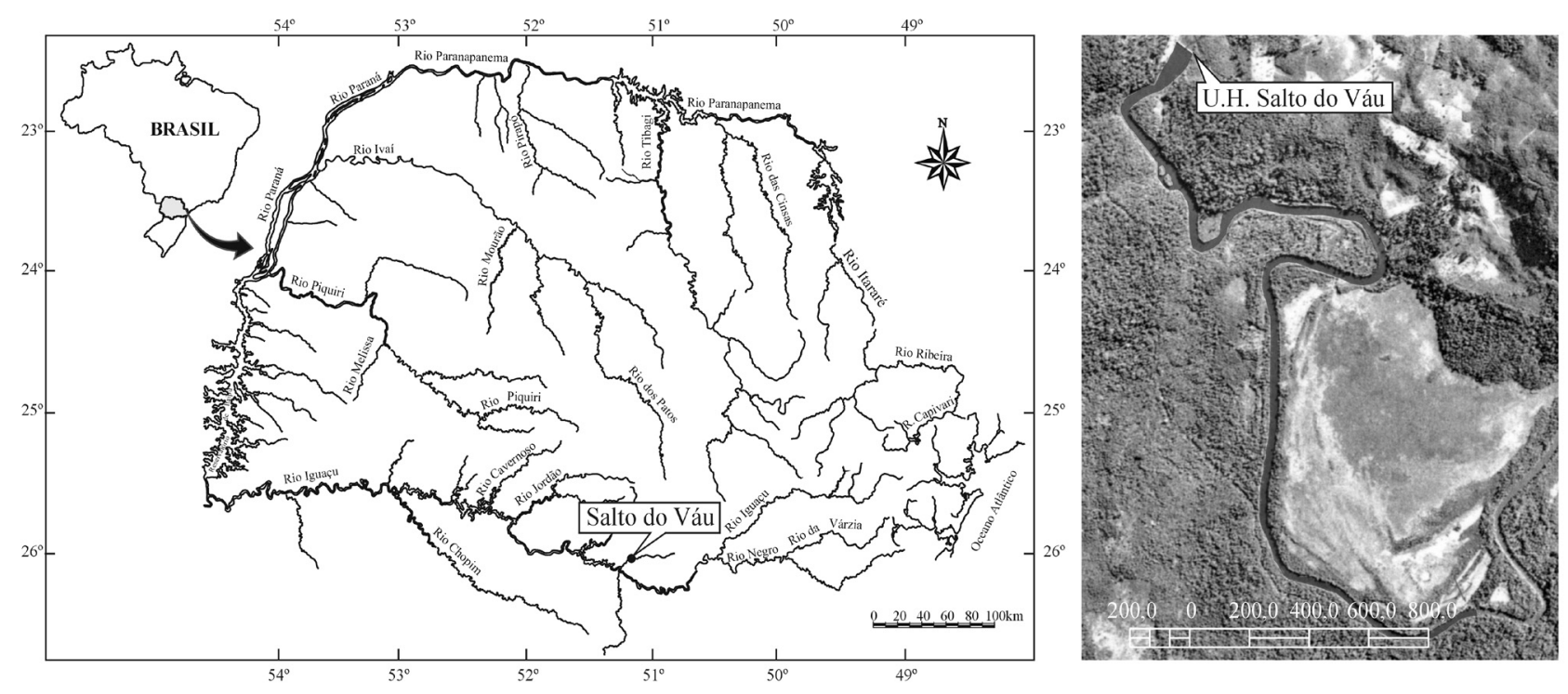

Figura 1. Localização do reservatório de Salto do Vau no Estado do Paraná, com detalhe de sua forma desde a região superior até a região das comportas da usina hidrelétrica.

\section{Cosmarium Corda}

Chave para os táxons de Cosmarium do reservatório de Salto do Vau

1. Parede celular pontuada ou lisa

2. Parede celular pontuada

3. Constrição celular mediana rasa

C. pseudoconnatum

3. Constrição celular mediana profunda

4. Seno mediano amplamente aberto, em forma de U .....

C. regnesii

4. Seno mediano aberto, em forma de $\mathrm{V}$

5. Semicélula oblonga

C. contractum

5. Semicélula hexagonal.

C. bioculatum

2. Parede celular lisa

6. Semicélula retangular a oblonga.....

C. minimum var. subrotundatum

6. Semicélula retangular, semicircular a subpiramidal ou subtrapeziforme

7. Semicélula retangular, com projeções laterais

C. regnellii

7. Semicélula subtrapeziforme ou semielíptica a subpiramidal

8. Semicélula subtrapeziforme

C. abbreviatum var. minus

8. Semicélula semielíptica a subpiramidal

9. Célula semielíptica a subpiramidal; $17,5-21$ x 11-13,5 $\mu \mathrm{m}$

C. laeve

9. Célula semicircular; $24-28$ x 20-23 $\mu \mathrm{m}$

C. subtumidum

1. Parede celular granulada

10. Seno mediano aberto

C. comissurale var. crassum

10. Seno mediano fechado

11. Semicélula reniforme

C. reniforme

11. Semicélula de outra forma

12. Cloroplasto com 1 pirenóide

13. Semicélula oblonga a trapeziforme

C. punctulatum

13. Semicélula semicircular a piramidal

Cosmarium sp.

12. Cloroplasto com 2 pirenóides 
14. Semicélula semicircular C. amoenum var. constricutm

14. Semicélula semicircular e/ou piramidal

15. Semicélula piramidal, com crenulações simples C. vexatum

15. Semicélula piramidal, com crenulações bigranuladas

16. Célula de 43-51 x 33-37 $\mu \mathrm{m}$, margens com menos de 22 granulações

C. subspeciosum

16. Célula de 77-98 x 61-70 $\mu \mathrm{m}$, margens com 22 granulações

C. subspeciosum var. validius

Cosmarium abbreviatum Raciborski var. minus (West \& West) Krieger \& Gerloff, Gattung Cosmarium 3-4: 242. 1965 ECosmarium abbreviatum Raciborski f. minor West \& West, Trans. Yorkshire Nat. Union 5(23): 92. 1900.

Figuras 6-8

Célula tão larga quanto longa ou 1,09-1,2 vez mais larga que longa; constrição mediana profunda, seno fechado; semicélula subtrapeziforme, ângulos basais arredondados, margens laterais levemente retusas na região mediana; ápices truncados; parede celular lisa; cloroplasto com 1 pirenóide em cada semicélula; vista lateral da semicélula circular, vista apical elíptica. Compr.: 9-12,5 um, larg.: 9-13,8 $\mu \mathrm{m}$, istmo: $2,8-4,7 \mu \mathrm{m}$.

Material examinado: BRASIL. PARANÁ: União da Vitória, Reservatório de Salto do Vau, região superior, 2-IV-2002, S.A. Felisberto s.n. (HUM11412); idem, região intermediária, 2-IV-2002, S.A. Felisberto s.n. (HUM11413); idem, região lacustre, 2-IV-2002, S.A. Felisberto s.n. (HUM11414); idem, região superior, 6-IX-2002, S.A. Felisberto s.n. (HUM11415); idem, região intermediária, 6-IX-2002, S.A. Felisberto s.n. (HUM11416).

Esta variedade difere da típica da espécie por apresentar tamanho menor, ângulos laterais menos arredondados e não proeminentes. C. abbreviatum var. minus foi identificado conforme Bicudo (1988, 1996), que propõem uma lista de sinonímia devido ao grande polimorfismo encontrado, sendo o mesmo observado no reservatório da Usina Hidrelétrica de Salto do Vau no presente estudo. Felisberto \& Rodrigues (2004) também reportaram tal polimorfismo no reservatório de Corumbá, Goiás.

Cosmarium amoenum Brébisson var. constrictum Scott \& Grönblad, Acta Soc. Sci. Fennicae II, B, 2(8): 15.1957.

Figuras 9-10
Célula 1,4-1,6 vez mais longa que larga; constrição mediana profunda, seno fechado; semicélula semicircular, levemente truncada no ápice, margens onduladas; ornamentações em toda a célula; parede celular granulada; cloroplasto com 2 pirenóides em cada semicélula; vista apical não observada. Compr.: 38-40,8 $\mu \mathrm{m}$, larg.: 23-26,5 $\mu \mathrm{m}$, istmo: 9-10 $\mu \mathrm{m}$.

Material examinado: BRASIL. Paraná: União da Vitória, Reservatório de Salto do Vau, região superior, 2-IV-2002, S.A. Felisberto s.n. (HUM11412); idem, região lacustre, 2-IV-2002, S.A. Felisberto s.n. (HUM11414).

Cosmarium bioculatum Brébisson in Ralfs, Brit. Desm. 95. 1848.

Figuras 11-13

Célula tão larga quanto longa; constrição mediana profunda, seno levemente fechado na região próxima ao istmo e aberto distalmente; semicélula hexagonal, oblonga (transversalmente subretangular); parede celular finamente pontuada; cloroplasto axial, 1 pirenóide; vista lateral da semicélula circular, vista apical elíptica. Compr.: 16,7-18,3 um, larg.: 17-17,5 $\mu \mathrm{m}$, istmo: 4,2-5,2 $\mu \mathrm{m}$.

Material examinado: BRASIL. PARANÁ: União da Vitória, Reservatório de Salto do Vau, região intermediária, 2-IV-2002, S.A. Felisberto s.n. (HUM11413).

Cosmarium comissurale (Brébisson) Ralfs var. crassum Nordstedt, Vidensk. Medd. Naturh. Foren. Kjobenhavn. 1869 (14-15): 213. 1870.

Figura 14

Célula uma vez mais larga que longa; constrição mediana profunda, seno aberto; semicélula subreniforme, parede celular granulosa, pontuada entre os grânulos; cloroplasto com 2 pirenóides, vista apical da célula elíptica, margens laterais intumescidas 
na porção mediana, constrita próximo dos ápices amplamente arredondados, inflados. Compr.: 30,8 $\mu \mathrm{m}$, larg.: 30-33,1 $\mu \mathrm{m}$, istmo: 10,5 $\mu \mathrm{m}$.

Material examinado: BRASIL. PARANÁ: União da Vitória, Reservatório de Salto do Vau, região intermediária, 2-IV-2002, S.A. Felisberto s.n. (HUM11413).

Cosmarium contractum Kirchner in West \& G.S. West, Monogr. Brit. Desm. 2: 170. 1878.

Figura 15

Célula 1,3 vez mais longa que larga; constrição mediana profunda, seno aberto, acutangular; semicélula oblonga (subcircular), margens convexas; ápice levemente convexo; parede celular finamente pontuada; cloroplasto axial, furcóide, 1 pirenóide por semicélula; vista lateral da semicélula circular, vista apical elíptica. Compr.: 16-21 $\mu \mathrm{m}$, larg.: 14,5-17,7 $\mu \mathrm{m}$, istmo: 5-6 $\mu \mathrm{m}$.

Material examinado: BRASIL. PARAná: União da Vitória, Reservatório de Salto do Vau, região lacustre, 2-IV-2002, S.A. Felisberto s.n. (HUM11414); idem, região intermediária, 6-IX-2002, S.A. Felisberto s.n. (HUM11416).

Cosmarium laeve Rabenhorst, Flor. Europ. Alg. 3: 161. 1868.

Figura 16

Célula 1,4-1,6 vez mais longa que larga; constrição mediana profunda, seno fechado; semicélula semielíptica a subpiramidal, margens laterais convexas; ápice estreito, truncado; parede celular lisa; cloroplasto com 1 pirenóide em cada semicélula; vista lateral da semicélula semicircular, vista apical oval-elíptica. Compr.: 17,5-25 $\mu \mathrm{m}$, larg.: 11,3-15 $\mu \mathrm{m}$, istmo: $3,8-5 \mu \mathrm{m}$.

Material examinado: BRASIL. PARAná: União da Vitória, Reservatório de Salto do Vau, região intermediária, 2-IV-2002, S.A. Felisberto s.n. (HUM11413); idem, região lacustre, 2-IV-2002, S.A. Felisberto s.n. (HUM11414); idem, região superior, 6-IX-2002, S.A. Felisberto s.n. (HUM11415).

Cosmarium minimum West \& G.S. West var. subrotundatum West \& G.S. West, Trans. Linn. Soc. London, Bot. II, 5(2): 59. 1895.

Figuras 17-19
Célula 1,2-1,3 vez mais longa que larga; constrição mediana profunda, seno fechado; semicélula retangular a oblonga, ângulos arredondados; parede celular lisa; cloroplasto com 1 pirenóide em cada semicélula; vista lateral da semicélula circular, vista apical elíptica. Compr.: 12-13 $\mu \mathrm{m}$, larg.: 9-12 $\mu \mathrm{m}$, istmo: 2,4-3,4 $\mu \mathrm{m}$.

Material examinado: BRASIL. PARANÁ: União da Vitória, Reservatório de Salto do Vau, região intermediária, 2-IV-2002, S.A. Felisberto s.n. (HUM11413).

Cosmarium pseudoconnatum Nordstedt, Vidensk. Medd. Naturh. Foren. Kjöbenhavn 1869 (14-15): 214. 1870 E Calocylindrus pseudoconnatus Nordstedt in Wolle, Bull. Torr. Club 8(11): 39. 1881.

Figuras 20-21

Célula 1-1,3 vez mais longa que larga; constrição mediana rasa, seno amplamente aberto; semicélula semicircular; parede celular pontuada; cloroplastídio axial, 4-radiado, pirenóides 4, 1 para cada projeção; vista lateral da semicélula igual à frontal, vista apical circular. Compr.: 45-55,2 $\mu \mathrm{m}$, larg.: 35-43,2 $\mu \mathrm{m}$, istmo: $32,5-39 \mu \mathrm{m}$.

Material examinado: BRASIL. PARANÁ: União da Vitória, Reservatório de Salto do Vau, região superior, 2-IV-2002, S.A. Felisberto s.n. (HUM11412); idem, região intermediária, 2-IV-2002, S.A. Felisberto s.n. (HUM11413); idem, região lacustre, 2-IV-2002, S.A. Felisberto s.n. (HUM11414).

Cosmarium punctulatum Brébisson, Liste Desm.: 129. 1856.

Figuras 22-23

Célula 1,1 vez mais longa que larga, às vezes tão longa quanto larga; constrição mediana profunda, seno mediano fechado; semicélula oblonga a trapeziforme, margens levemente onduladas, ângulos basais e apicais arredondados; cloroplasto com 1 pirenóide em cada semicélula; vista lateral da semicélula semicircular, vista apical elíptica, com uma leve intumescência mediana. Compr.: 24-27 $\mu \mathrm{m}$, larg.: 22-25 $\mu \mathrm{m}$, istmo: $11 \mu \mathrm{m}$.

Material examinado: BRASIL. PARAnÁ: União da Vitória, Reservatório de Salto do Vau, região intermediária, 2-IV-2002, S.A. Felisberto s.n. (HUM11413); idem, região lacustre, 2-IV-2002, S.A. Felisberto s.n. (HUM11414); idem, região lacustre, 6-IX-2002, S.A. Felisberto s.n. (HUM11417). 

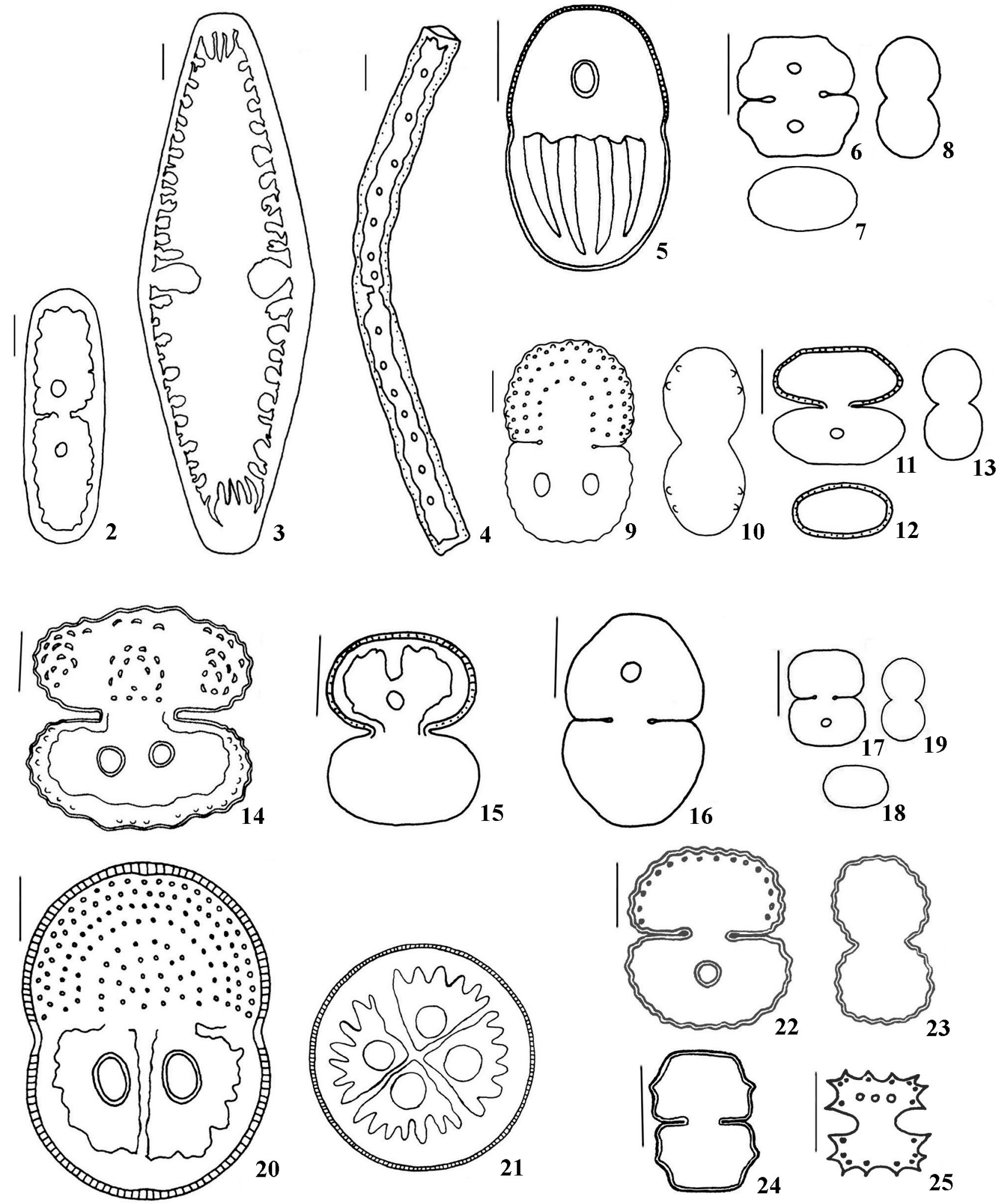

Figuras 2-25. Espécies de Mesotaeniaceae, Gonatozygaceae e Desmidiaceae do reservatório de Salto do Vau. 2. Cylindrocystis brebissonii. 3. Netrium digitus. 4. Gonatozygon monotaenium. 5. Actinotaenium globosum. 6-8. Cosmarium abbreviatum var. minus. 9-10. Cosmarium amoenum var. constrictum. 11-13. Cosmarium bioculatum. 14. Cosmarium comissurale var. crassum. 15. Cosmarium contractum. 16. Cosmarium laeve. 17-19. Cosmarium minimum var. subrotundatum. 20-21. Cosmarium pseudoconnatum. 22-23. Cosmarium punctulatum. 24. Cosmarium regnellii. 25. Cosmarium regnesii. Barras de escala $=10 \mu \mathrm{m}$. 
Cosmarium regnellii Wille, Bih. Kongl. Svenska Vet.-Akad. Handl. 8(18): 16. 1884.

\section{Figura 24}

Célula 1,1-1,2 vez mais longa que larga; constrição mediana profunda, seno fechado; semicélula retangular, margens laterais lisas com uma projeção em cada margem; margens convergindo abruptamente para o ápice; ângulos basais e apicais arredondados e ápice amplamente truncado; parede celular lisa; cloroplasto com 1 pirenóide em cada semicélula; vista lateral da semicélula subcircular, vista apical oblonga. Compr.: 13-15 $\mu \mathrm{m}$, larg.: $12 \mu \mathrm{m}$, istmo: 3,2-4 $\mu \mathrm{m}$.

Material examinado: BRASIL. PARANÁ: União da Vitória, Reservatório de Salto do Vau, região intermediária, 2-IV-2002, S.A. Felisberto s.n. (HUM11413); idem, região superior, 6-IX-2002, S.A. Felisberto s.n. (HUM11415).

\section{Cosmarium regnesii Reinsch, Act. Soc. Senckenberg}

6: 116.1867.

Figura 25

Célula tão longa quanto larga; constrição mediana profunda, seno amplamente aberto em forma de $\mathrm{U}$; semicélula subretangular, margens apical e laterais denteadas; parede celular lisa; cloroplasto axial, pirenóide 1 em cada semicélula; vista apical da célula elíptica, 2 dentes apicais, 3 protuberâncias de cada lado. Compr.: 12-13 $\mu \mathrm{m}$, larg.: 12-13 $\mu \mathrm{m}$, istmo: 4-5 $\mu \mathrm{m}$.

Material examinado: BRASIL. PARANÁ: União da Vitória, Reservatório de Salto do Vau, região intermediária, 2-IV-2002, S.A. Felisberto s.n. (HUM11413).

Cosmarium reniforme (Ralfs) Archer, Jour. Bot. 12: 92. 1874 =Cosmarium margaritiferum Meneghini var. reniformis Ralfs, Brit. Desm. 1848: 100. 1848.

Figura 26

Célula 1,0-1,2 vez mais longa que larga; constrição mediana profunda, seno levemente aberto a fechado; semicélula reniforme, margens onduladas; ornamentações em toda a célula; parede celular granulada; cloroplasto com 2 pirenóides em cada semicélula; vista lateral da semicélula circular, vista apical oblonga. Compr.: 43,4-44 $\mu \mathrm{m}$, larg.: 36-41 $\mu \mathrm{m}$, istmo: $12-16 \mu \mathrm{m}$.

Material examinado: BRASIL. Paraná: União da Vitória, Reservatório de Salto do Vau, região intermediária, 2-IV-2002, S.A. Felisberto s.n. (HUM11413); idem, região superior, 6-IX-2002, S.A. Felisberto s.n. (HUM11415); idem, região intermediária, 6-IX-2002, S.A. Felisberto s.n. (HUM11416); idem, região lacustre, 6-IX-2002, S.A. Felisberto s.n. (HUM11417).

Cosmarium subspeciosum Nordstedt var. subspeciosum Öfv., Kongl. Vet.-Akad. Förhandl. 22: 13.1875.

Figuras 27-28

Célula 1,3-1,4 vez mais longa que larga; constrição mediana profunda, seno fechado; semicélula semicircular a piramidal, margens laterais com 5 a 7 crenulações bigranuladas, apical com 4; parede celular granulosa com pares de grânulos em séries radiais, 1 protuberância na região central da semicélula; cloroplasto com 2 pirenóides em cada semicélula; vista lateral da semicélula oblonga, pólo apical arredondado, margens laterais infladas, vista apical

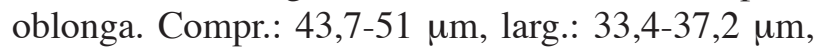
istmo: $12,5-13 \mu \mathrm{m}$.

Material examinado: BRASIL. PARAná: União da Vitória, Reservatório de Salto do Vau, região superior, 2-IV-2002, S.A. Felisberto s.n. (HUM11412); idem, região intermediária, 2-IV-2002, S.A. Felisberto s.n. (HUM11413); idem, região lacustre, 2-IV-2002, S.A. Felisberto s.n. (HUM11414).

Cosmarium subspeciosum Nordstedt var. validius Nordstedt, Kongl. Svenska Vet.-Akad. Handl., 22(8): 49. 1888.

Figura 29

Célula 1,3-1,4 mais longa que larga; constrição mediana profunda, seno levemente aberto a fechado; semicélula semicircular a piramidal, truncada; ângulos basais arredondados, margens com 22 bicrenulações; parede celular granulada, par de grânulos em séries radiais; uma série de grânulos acima do istmo; cloroplasto com 2 pirenóides em cada semicélula; vista lateral da semicélula oblonga, pólo apical arredondado, margens laterais infladas, vista apical

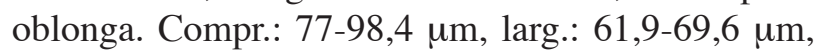
istmo: $18-22 \mu \mathrm{m}$.

Material examinado: BRASIL. PARANÁ: União da Vitória, Reservatório de Salto do Vau, região intermediária, 2-IV-2002, S.A. Felisberto s.n. (HUM11413); idem, região lacustre, 2-IV-2002, 
S.A. Felisberto s.n. (HUM11414); idem, região intermediária, 6-IX-2002, S.A. Felisberto s.n. (HUM11416).

A variedade validius difere da típica por apresentar dimensões celulares maiores.

Cosmarium subtumidum Nordstedt in Wittrock \& Nordstedt, Alg. Exsicc. 172(21): 44. 1889.

Figura 30

Célula 1,2-1,4 vez mais longa que larga; constrição mediana profunda, seno fechado; semicélula semicircular em vista frontal (aparência subpiramidal) com ângulos arredondados a levemente truncado nos ápices; parede celular lisa; cloroplasto com 1 pirenóide em cada semicélula; vista lateral da semicélula elíptica, vista apical oval. Compr.: 24-28 um, larg.: 20-23 $\mu \mathrm{m}$, istmo: 4-8 $\mu \mathrm{m}$.

Material examinado: BRASIL. PARANÁ: União da Vitória, Reservatório de Salto do Vau, região intermediária, 2-IV-2002, S.A. Felisberto s.n. (HUM11413).

Cosmarium vexatum West, Jour. Roy. Microsc. Soc. 1892: 33. 1892a.

Figuras 31-33

Célula 1,1 vez mais longa que larga; constrição mediana profunda, seno fechado; semicélula piramidal, margens onduladas e ápice truncado; parede celular pontuada; cloroplasto com 2 pirenóides em cada semicélula; vista lateral da semicélula semicircular, vista apical oval, com uma leve proeminência na região mediana. Compr.: $32 \mu \mathrm{m}$, larg.: 24-28 $\mu \mathrm{m}$, istmo: $10 \mu \mathrm{m}$.

Material examinado: BRASIL. PARANÁ: União da Vitória, Reservatório de Salto do Vau, região intermediária, 2-IV-2002, S.A. Felisberto s.n. (HUM11413); idem, região lacustre, 2-IV-2002, S.A. Felisberto s.n. (HUM11414); idem, região lacustre, 6-IX-2002, S.A. Felisberto s.n. (HUM11417).

\section{Cosmarium sp.}

Figuras 34-35

Célula 1-1,2 vez mais longa que larga; constrição mediana profunda, seno fechado; semicélula semicircular a piramidal, margens onduladas, ângulos basais e apicais arredondados; parede celular granulada; cloroplasto com 1 pirenóide; vista lateral da semicélula semicircular. Compr.: 24-28 um, larg.: 22-23,8 $\mu \mathrm{m}$, istmo: 8-9 $\mu \mathrm{m}$.
Material examinado: BRASIL. PARANÁ: União da Vitória, Reservatório de Salto do Vau, região lacustre, 2-IV-2002, S.A. Felisberto s.n. (HUM11414).

Cosmarium sp. assemelha-se muito a $C$. punctulatum e $C$. vexatum, porém difere do primeiro por possuir semicélula com contorno mais piramidal, enquanto em $C$. punctulatum é mais trapeziforme. Cosmarium sp. difere de $C$. vexatum quanto ao número de pirenóides, que neste último são dois por semicélula. A investigação deste táxon foi baseada em análise populacional, sendo assim preferiu-se identifica-lo como Cosmarium sp.

\section{Euastrum Ehrenberg}

Chave para os táxons de Euastrum do reservatório de Salto do Vau

1. Semicélula trapeziforme E. insulare

1. Semicélula subtrapeziforme

2. Incisão mediana apical rasa, 60-64 × 48-50 um E. gemmatum

2. Incisão mediana apical profunda, 24-29 × 19-23 um E. denticulatum

Euastrum denticulatum Gay, Bull. Soc. Fr. 31: 335. 1884.

\section{Figuras 36-37}

Célula 1,1-1,3 vez mais longa que larga; constrição mediana profunda, seno fechado; semicélula subtrapeziforme, margens laterais onduladas, lobos basais retangulares, incisão mediana apical profunda, espinho curto nos ângulos apicais; parede celular ornada com grânulos; cloroplasto com um pirenóide por semicélula; vista lateral da semicélula oval, vista apical elíptica. Compr.: 24-28,8 um, larg.: 19-22,8 $\mu \mathrm{m}$, istmo: 4,8-6 $\mu \mathrm{m}$.

Material examinado: BRASIL. PARAnÁ: União da Vitória, Reservatório de Salto do Vau, região superior, 2-IV-2002, S.A. Felisberto s.n. (HUM11412); idem, região intermediária, 2-IV-2002, S.A. Felisberto s.n. (HUM11413); idem, região lacustre, 2-IV-2002, S.A. Felisberto s.n. (HUM11414); idem, região superior, 6-IX-2002, S.A. Felisberto s.n. (HUM11415); idem, região intermediária, 6-IX-2002, S.A. Felisberto s.n. (HUM11416); idem, região lacustre, 6-IX-2002, S.A. Felisberto s.n. (HUM11417).

Euastrum gemmatum (Brébisson) Ralfs, Brit. Desm. 87(14): 4.1848 = Cosmarium gemmatum Brébisson in Meneghini, Synop. Desm. 1840: 221. 1840. 
Figuras 38-39

Célula 1,2-1,3 vez mais longa que larga; constrição mediana profunda, seno fechado; semicélula subtrapeziforme, 3-lobada; parede celular esparsamente granulosa, 3 séries de grânulos, sendo o central mais evidente; lobo apical subcuneiforme inteiro, com incisão mediana rasa; lobos basais bilobulados, lóbulos levemente voltados para cima; vista lateral da semicélula oval-truncada; vista apical

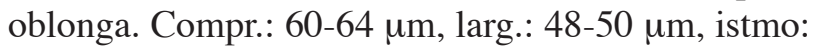
12-14 um.

Material examinado: BRASIL. PARANÁ: União da Vitória, Reservatório de Salto do Vau, região intermediária, 2-IV-2002, S.A. Felisberto s.n. (HUM11413); idem, região lacustre, 2-IV-2002, S.A. Felisberto s.n. (HUM11414).

Euastrum insulare (Wittr.) Roy, Monogr. Scott. Nat. 1877: 68. 1877 E Euastrum binale (Turp.) Ehrenberg ex Ralfs var. insulare Wittr., Bih. Kongl. Vet.-Akad. Handl. 1: 49. 1872.

Figuras 40-41

Célula 1,3 vez mais longa que larga; constrição mediana profunda, seno fechado; semicélula trapeziforme, margens laterais levemente onduladas, lobos basais retangulares, incisão mediana apical profunda; parede celular lisa; cloroplasto com um pirenóide por semicélula; vista lateral da semicélula oval, margens laterais com 1 mamilo mediano; vista apical elíptica. Compr.: 24-25,8 $\mu \mathrm{m}$, larg.: 17,5-19 $\mu \mathrm{m}$, istmo: 3,7-4,5 $\mu \mathrm{m}$.

Material examinado: BRASIL. PARANÁ: União da Vitória, Reservatório de Salto do Vau, região intermediária, 2-IV-2002, S.A. Felisberto s.n. (HUM11413).

\section{Hyalotheca Ehrenberg}

Hyalotheca dissiliens (Smith) Brébisson ex Ralfs, Brit. Desm. 51. 1848 = Conferva dissiliens Smith, Bot. Brit. Plants 35: 2464. 1812.

Figura 42

Célula 1,1-1,7 vez mais larga que longa; constrição mediana rasa; semicélula retangular, margens laterais convexas; células unidas por seus ápices formando filamentos constritos nas junções; parede celular lisa; cloroplasto com um pirenóide. Compr.: 12-16,8 $\mu \mathrm{m}$, larg.: 18,3-28 $\mu \mathrm{m}$.

Material examinado: BRASIL. PARANá: União da Vitória, Reservatório de Salto do Vau, região superior, 2-IV-2002, S.A. Felisberto s.n. (HUM11412); idem, região intermediária, 2-IV-2002, S.A. Felisberto s.n. (HUM11413); idem, região lacustre, 2-IV-2002, S.A. Felisberto s.n. (HUM11414); idem, região superior, 6-IX-2002, S.A. Felisberto s.n. (HUM11415); idem, região intermediária, 6-IX-2002, S.A. Felisberto s.n. (HUM11416); idem, região lacustre, 6-IX-2002, S.A. Felisberto s.n. (HUM11417).

\section{Micrasterias Agardh}

Chave para os táxons de Micrasterias do reservatório de Salto do Vau

1. Semicélula 3-lobada M. laticeps var. laticeps

1. Semicélula 5-lobada

2. Parede celular com grânulos ou espinhos

3. Lobos laterais e basais divididos em lóbulos; parede celular com espinhos

M. radiosa var. elegantior

3. Lobos laterais e basais indivisos; parede celular com grânulos intramarginais ao longo das incisões M. mahabuleshwarensis

2. Parede celular lisa ou pontuada

4. Célula menor que $100 \mu \mathrm{m}$ compr. M. truncata var. pusilla

4. Célula maior que $100 \mu \mathrm{m}$ compr.

5. Lobos basais com 2 lóbulos M. excavata var. excavata

5. Lobos basais com 4 ou mais lóbulos

6. Lobos basais com 4 lóbulos M. rotata

6. Lobos basais com (7-)8 lóbulos M. radiosa var. radiosa 

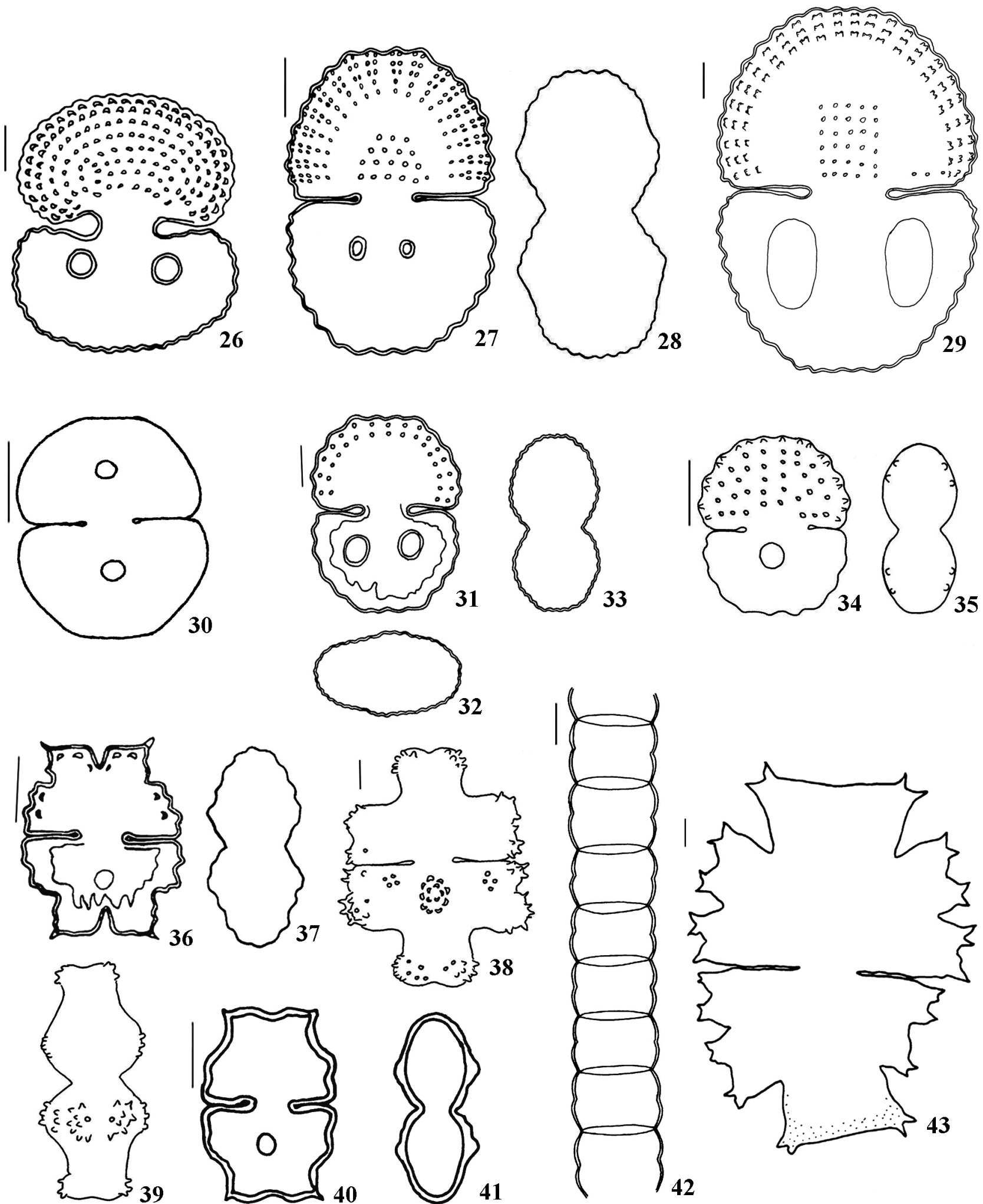

39
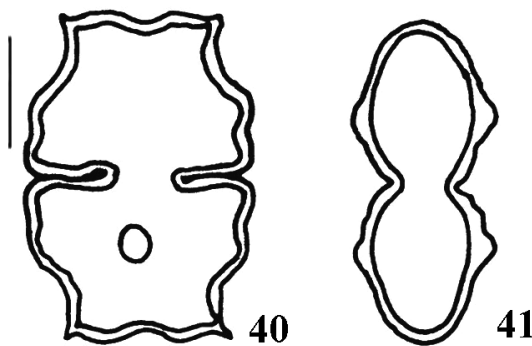

42

Figuras 26-43. Espécies de Desmidiaceae do reservatório de Salto do Vau. 26. Cosmarium reniforme. 27-28. Cosmarium subspeciosum var. subspeciosum. 29. Cosmarium subspeciosum var. validius. 30. Cosmarium subtumidum. 31-33. Cosmarium vexatum. 34-35. Cosmarium sp. 36-37. Euastrum denticulatum. 38-39. Euastrum gemmatum. 40-41. Euastrum insulare. 42. Hyalotheca dissiliens. 43. Micrasterias excavata var. excavata. Barras de escala $=10 \mu \mathrm{m}$. 
Micrasterias excavata (Nordstedt) Bicudo \& Sormus var. excavata, Biblioth. Phycol. 57: 35. 1982.

Figura 43

Célula 1,3 vez mais longa que larga; constrição mediana profunda, seno fechado na parte proximal, aberto na distal; semicélula 5-lobada, incisões interlobares abertas; lobo apical subretangular, projetado além das laterais, margens laterais subparalelas ou levemente divergentes para o ápice, margem apical reta ou pouco convexa ou com uma suave depressão mediana, extremidades (1)2denticuladas; lobos laterais e basais de tamanhos aproximadamente iguais, cada qual subdividido por uma incisão rasa, geralmente arredondada em 2 lóbulos 2-denticulados; parede celular pontuada. Compr.: $166 \mu \mathrm{m}$, larg.: $124 \mu \mathrm{m}$, istmo: $22 \mu \mathrm{m}$.

Material examinado: BRASIL. PARANÁ: União da Vitória, Reservatório de Salto do Vau, região lacustre, 2-IV-2002, S.A. Felisberto s.n. (HUM11414).

Micrasterias laticeps Nordstedt var. laticeps, Vidensk. Medd. Naturh. Foren. 1869 (14-15): 220. 1870.

Figura 44

Célula 1,2-1,3 vezes mais larga que longa; constrição mediana profunda, seno aberto; semicélula de contorno semicircular, 3-lobada, incisões interlobares profundas, abertas, lobo apical transversalmente fusiforme, margem apical convexa, às vezes retusa no meio, ângulos acuminados, lobos basais semifusiformes, dispostos horizontalmente, 2-denticulados; parede celular finamente pontuada. Compr.: 112,5-127,4 $\mu \mathrm{m}$, larg.: 147,5-151,2 $\mu \mathrm{m}$, istmo: $19,2-22,5 \mu \mathrm{m}$.

Material examinado: BRASIL. PARANÁ: União da Vitória, Reservatório de Salto do Vau, região superior, 6-IX-2002, S.A. Felisberto s.n. (HUM11415); idem, região intermediária, 6-IX-2002, S.A. Felisberto s.n. (HUM11416).

Em alguns indivíduos observou-se variabilidade morfológica quanto aos lobos basais, com um deles apresentando extremidades bifurcadas, enquanto no outro lado estas não se apresentaram bifurcadas.

Micrasterias mahabuleshwarensis Hobson, Quart. Jour. Microsc. Sci. 1836: 169. 1863.

\section{Figura 45}

Célula 1,2 vez mais longa que larga; constrição mediana profunda, seno aberto; semicélula de contorno semielíptico, 5-lobada, incisões interlobares profundas, abertas, lobo apical subcilíndrico, ápice retuso, ângulos projetados em processos divergentes, 3-denticulados, 1 par de processos acessórios, assimétricos, 3-denticulados, lobos laterais e basais cônico-truncados, inteiros, extremidades 3-denticulada; parede celular granulosa. Compr.: 152 $\mu \mathrm{m}$, larg.: $134 \mu \mathrm{m}$, istmo: $24 \mu \mathrm{m}$.

Material examinado: BRASIL. PARANÁ: União da Vitória, Reservatório de Salto do Vau, região lacustre, 2-IV-2002, S.A. Felisberto s.n. (HUM11414).

Micrasterias radiosa Ralfs var. radiosa, Brit. Desm.: 72. 1848.

Figura 46

Célula tão longa quanto larga, constrição mediana profunda, seno aberto nas extremidades; semicélula 5-lobada, incisões interlobares profundas, geralmente abertas; lobo apical aproximadamente cuneiforme, alongado, não projetado além dos lobos laterais, margens laterais subparalelas, divergentes para o ápice, margem apical ligeiramente côncava, com incisão mediana arredondada, (1)2 dentículos de cada lado, extremidades com (2)3 dentículos cada; lobos laterais e basais de tamanhos aproximadamente iguais, cada qual subdividido por 7 incisões estreitas (1 mais profunda, 2 de profundidade média e 4 pouco profundas) em 8 lóbulos (2-)3-4(-5) denticulado; parede celular lisa. Compr.: 128,5 $\mu \mathrm{m}$, larg.: 128,5 $\mu \mathrm{m}$, istmo: $12,8 \mu \mathrm{m}$.

Material examinado: BRASIL. PARANÁ: União da Vitória, Reservatório de Salto do Vau, região intermediária, 2-IV-2002, S.A. Felisberto s.n. (HUM11413).

Micrasterias radiosa Ralfs var. elegantior (G.S. West) Croasdale, Syn. N. A. Desm. 132: 2. 1977 = Micrasterias sol var. ornata f. elegantior G.S. West, Mém. Soc. Sci. nature. Neuchatel 5: 1031. 1914.

Figura 47

Célula 1-1,1 vezes mais longa que larga; constrição mediana profunda, seno levemente fechado, às vezes, aberto nas extremidades; semicélula 5-lobada, incisões interlobares profundas, geralmente abertas; lobo apical aproximadamente cuneiforme, alongado, não projetado além dos lobos laterais, margens laterais subparalelas, divergentes para o 
ápice, margem apical ligeiramente côncava, com incisão mediana arredondada, (1)2 dentículos de cada lado, extremidades (2)3 dentículos cada; lobos laterais e basais de tamanhos aproximadamente iguais, cada qual subdividido por 7 incisões estreitas ( 1 mais profunda, 2 de profundidade média e 4 pouco profundas) em 8 lóbulos (2)3-4(5) denticulados; parede celular pontuada, com espinhos parecendo faltar. Compr.: 140-264,6 $\mu \mathrm{m}$, larg.: 138-237,6 $\mu \mathrm{m}$, istmo: $14,4-28,8 \mu \mathrm{m}$.

Material examinado: BRASIL. PARANÁ: União da Vitória, Reservatório de Salto do Vau, região intermediária, 6-IX-2002, S.A. Felisberto s.n. (HUM11416).

Micrasterias rotata (Greville) Ralfs ex Ralfs, Ann. Mag. nat. Hist. 14: 259. 1844. = Echinella rotata Greville in Hooker, Brit. Flora 2: 398. 1833.

Figura 48

Célula 1-1,2 vezes mais longa que larga; constrição mediana profunda, seno fechado; semicélula de contorno semicircular, 5-lobada, incisões interlobares profundas, semiabertas; lobo apical subcilíndrico, projetado além dos laterais; ápice retuso-chanfrado; ângulos projetados formando processos cônicos, 2-denticulados; lobos laterais subdivididos até $3^{\text {a }}$ ordem, ambos com extremidades 2-denticulada; parede celular finamente pontuada. Compr.: 246-264 $\mu \mathrm{m}$, larg.: 215,6-245 $\mu \mathrm{m}$, istmo: 33,6-36 $\mu \mathrm{m}$.

Material examinado: BRASIL. PARAnÁ: União da Vitória, Reservatório de Salto do Vau, região lacustre, 2-IV-2002, S.A. Felisberto s.n. (HUM11414); idem, região intermediária, 6-IX-2002, S.A. Felisberto s.n. (HUM11416).

Observou-se variabilidade quanto aos lobos basais, que em apenas um lado apresentaram-se arredondados como na variedade japonica, mas como este fato ocorreu apenas em um dos indivíduos analisados optou-se por identificá-lo como pertencendo à variedade típica.

Micrasterias truncata (Corda) Brébisson ex Ralfs var. pusilla G.S. West, Mém. Soc. Neuchât. Sci. Nat. 5: 1035. 1914.

Figura 49

Célula 1,1 vez mais larga que longa, às vezes tão larga quanto longa; constrição mediana profunda, seno aberto; semicélula semicircular a retangular, 5-lobada, incisões interlobares abertas entre os lobos laterais, profundamente abertas entre os lobos laterais e o apical; lobo lateral bilobado com incisão rasa, aberta entre os lóbulos, bidenticulado; dentículos de tamanhos iguais ou levemente diferentes; lobo apical subfusiforme, levemente cuneado, ápice truncado ou levemente convexo, às vezes com uma depressão mediana, suave, ângulos acuminados; parede celular pontuada; um cloroplasto por semicélula. Compr.: 5256,2 um, larg.: 60,4-63,6 $\mu \mathrm{m}$, istmo 10,8-11,5 $\mu \mathrm{m}$.

Material examinado: BRASIL. PARANÁ: União da Vitória, Reservatório de Salto do Vau, região lacustre, 2-IV-2002, S.A. Felisberto s.n. (HUM11414).

Micrasterias truncata var. pusilla difere da variedade típica da espécie por possuir medidas menores.

\section{Pleurotaenium Nägeli}

Pleurotaenium ehrenbergii (Brébisson) De Bary, Unt. Fam. Conjug. 75. 1858.

Figuras 50-51

Célula 12,6-15,5 vezes mais longa que larga, cilíndrica; constrição mediana rasa, seno linear; margens laterais onduladas próximo à região mediana e retilíneas em direção às extremidades; pólos amplamente truncados, ornados com grânulos; parede celular lisa; cloroplasto com vários pirenóides. Compr.: 280,6-627,2 $\mu \mathrm{m}$, larg.: 25,5-41,5 $\mu \mathrm{m}$, istmo: 22,4-30 $\mu \mathrm{m}$.

Material examinado: BRASIL. ParanÁ: União da Vitória, Reservatório de Salto do Vau, região superior, 2-IV-2002, S.A. Felisberto s.n. (HUM11412); idem, região intermediária, 2-IV-2002, S.A. Felisberto s.n. (HUM11413); idem, região lacustre, 2-IV-2002, S.A. Felisberto s.n. (HUM11414); idem, região superior, 6-IX-2002, S.A. Felisberto s.n. (HUM11415); idem, região intermediária, 6-IX-2002, S.A. Felisberto s.n. (HUM11416).

\section{Spondylosium Brébisson}

Spondylosium planum (Wolle) West \& G.S. West, J. Linn. Soc., sér. Bot., 40: 430. 1912 =Sphaerozosma pulchrum Bailey var. planum Wolle, Desm. U.S.: 29. 1884.

Figura 52 

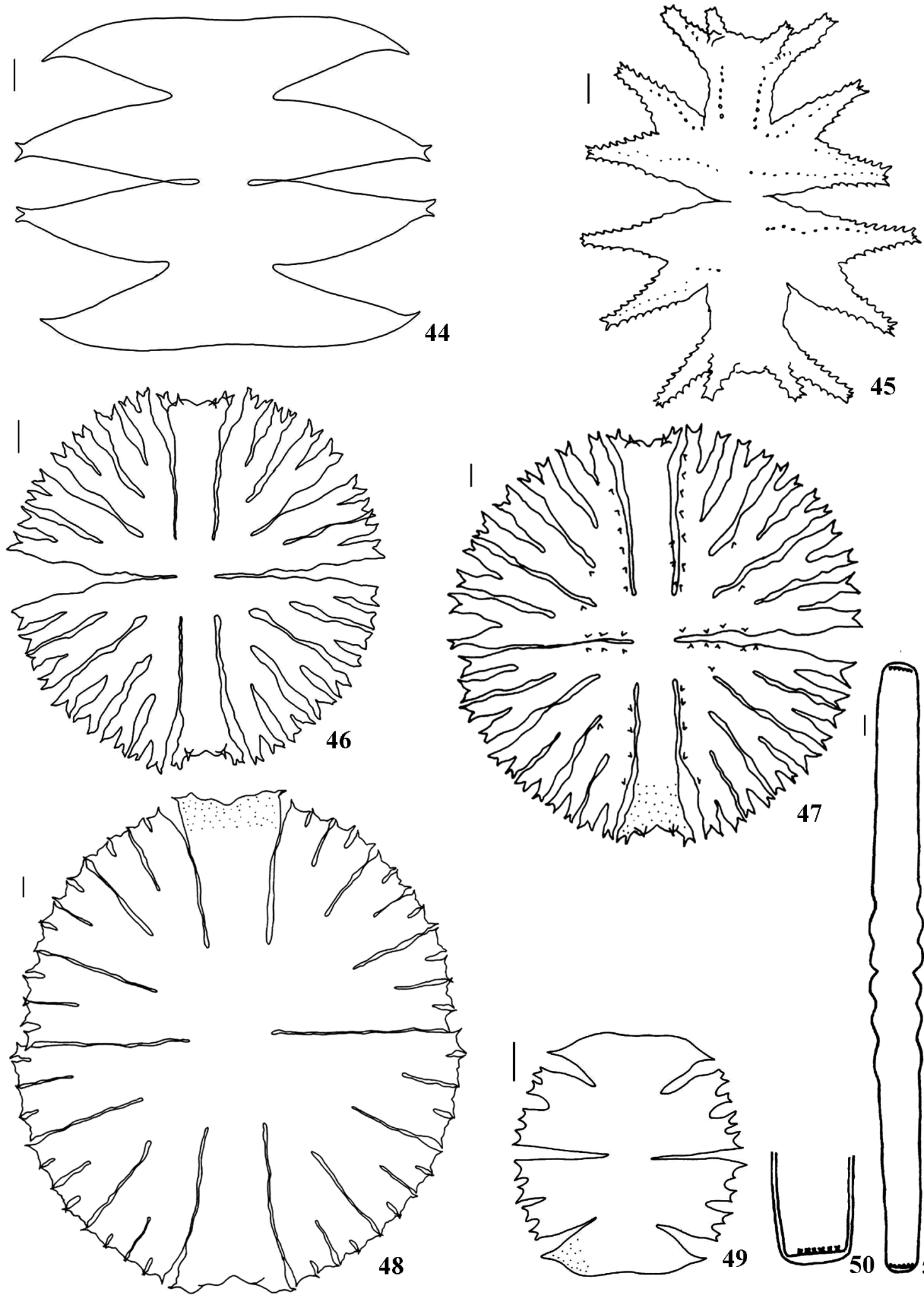

Figuras 44-52. Espécies de Desmidiaceae do reservatório de Salto do Vau. 44. Micrasterias laticeps var. laticeps. 45. Micrasterias mahabuleshwarensis. 46. Micrasterias radiosa var. radiosa. 47. Micrasterias radiosa var. elegantior. 48. Micrasterias rotata. 49. Micrasterias truncata var. pusilla. 50-51. Pleurotaenium ehrenbergii. 52. Spondylosium planum. Barras de escala $=10 \mu \mathrm{m}$. 
Célula 1,0-1,2 vez mais longa que larga ou quadrática; filamento não torcido, sem bainha de mucilagem; constrição mediana profunda, seno aberto; semicélula oblonga, margens laterais arredondadas, margem superior reta; células unidas pela justaposição das margens superiores; parede celular lisa; cloroplasto com um pirenóide por semicélula. Compr.: 9-12 $\mu \mathrm{m}$, larg.: 9-11 $\mu \mathrm{m}$, istmo: 4-6 $\mu \mathrm{m}$.

Material examinado: BRASIL. PARAnÁ: União da Vitória, Reservatório de Salto do Vau, região intermediária, 6-IX-2002, S.A. Felisberto s.n. (HUM11416).

\section{Staurastrum Meyen}

Chave para os táxons de Staurastrum do reservatório de Salto do Vau

1. Células com espinhos ou processos

2. Parede celular crenulada, vista apical com 6 processos S. margaritaceum

2. Parede celular lisa

3. Semicélula subcuneiforme S. trifidum var. inflexum

3. Semicélula elíptica a oblonga

4. Célula com espinhos e processos, vista apical com 9 processos

S. hantzschii

4. Célula apenas com espinhos

5. Espinhos curtos em toda a margem da semicélula S. claviferum

5. Espinhos longos, mais espalhados nas margens S. setigerum

1. Células sem espinhos ou processos

6. Parede celular lisa

7. Semicélula semicircular, levemente truncada no ápice S. orbiculare var. orbiculare

7. Semicélula semicircular, achatada longitudinalmente S. orbiculare var. depressum

6. Parede celular crenulada

8. Parede celular com grânulos, vista apical quadrangular S. disputatum

8. Parede celular com grânulos, vista apical triangular S. alternans

Staurastrum alternans Brébisson, Brit. Desm. 132. 1848.

Figuras 53-54

Célula 1,1 vez mais longa que larga; constrição mediana profunda, seno aberto; semicélula elíptica com lobos alternando; margens serreadas; parede celular ornamentada com grânulos; cloroplasto com um pirenóide por semicélula; vista apical de semicélula triangular. Compr.: 24-28 um, larg.: 21,6$28 \mu \mathrm{m}$, istmo: 7-10 $\mu \mathrm{m}$.

Material examinado: BRASIL. Paraná: União da Vitória, Reservatório de Salto do Vau, região intermediária, 2-IV-2002, S.A. Felisberto s.n. (HUM11413); região superior, 6-IX-2002, S.A. Felisberto s.n. (HUM11415); idem, região intermediária, 6-IX-2002, S.A. Felisberto s.n. (HUM11416); idem, região lacustre, 6-IX-2002, S.A. Felisberto s.n. (HUM11417).
Staurastrum claviferum West \& G.S. West, Trans. Linn. Soc. London, Bot. II, 5(2): 259. 1896.

Figuras 55-57

Célula longa longa quanto larga; constrição mediana profunda, seno aberto; semicélula elíptica, margens laterais arredondadas, margem superior convexa; espinhos curtos em todas as margens, mais desenvolvidos nos ângulos; parede celular lisa; cloroplasto com um pirenóide por semicélula; vista apical da semicélula triangular, com espinhos em fileira, ângulos arredondados, com três ou quatro espinhos um pouco mais largos que os espinhos marginais. Compr.: 37,3 um, larg.: 34-36 $\mu \mathrm{m}$ (com espinhos), istmo: 11,6 $\mu \mathrm{m}$, esp.: 1,3 $\mu \mathrm{m}$.

Material examinado: BRASIL. PARANÁ: União da Vitória, Reservatório de Salto do Vau, região superior, 2-IV-2002, S.A. Felisberto s.n. (HUM11412); idem, região intermediária, 6-IX-2002, S.A. Felisberto s.n. (HUM11416). 

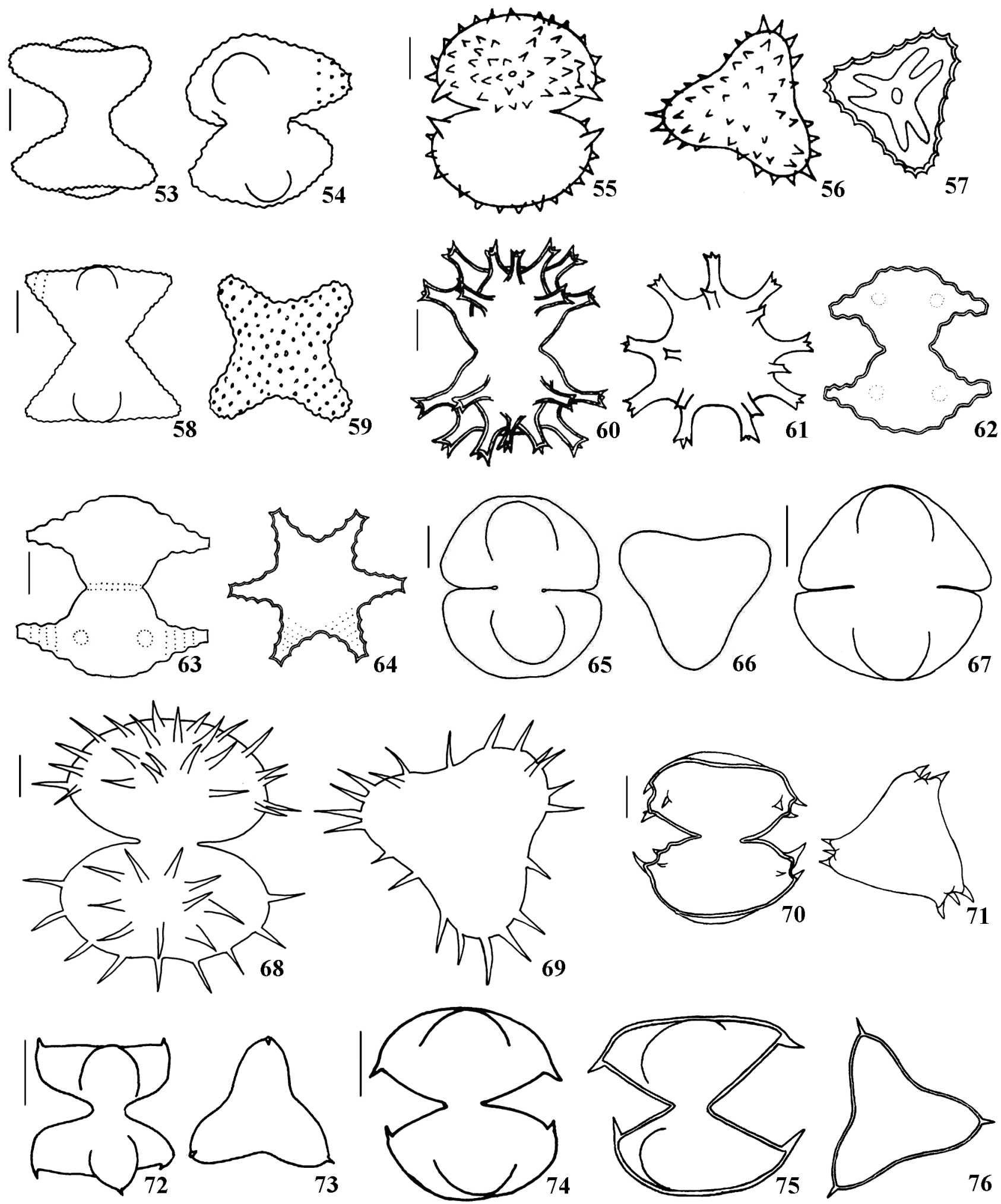

Figuras 53-76. Espécies de Desmidiaceae do reservatório de Salto do Vau. 53-54. Staurastrum alternans. 55-57. Staurastrum claviferum. 58-59. Staurastrum disputatum. 60-61. Staurastrum hantzschii. 62-64. Staurastrum margaritaceum. 65-66. Staurastrum orbiculare. 67. Staurastrum orbiculare var. depressum. 68-69. Staurastrum setigerum. 70-71. Staurastrum trifidum var. inflexum. 72-73. Staurodesmus dejectus var. apiculatus. 74-76. Staurodesmus dickiei. Barras de escala $=10 \mu \mathrm{m}$. 
Staurastrum disputatum West \& G.S. West, Monogr. Brit. Desm. 126: 16. 1912.

Figuras 58-59

Célula 1,1 vez mais longa que larga ou as vezes tão longa quanto larga; constrição mediana profunda, seno aberto; semicélula obtrapeziforme com extremidades arredondadas; margens serreadas; parede celular ornamentada com grânulos; cloroplasto com um pirenóide por semicélula; vista apical da semicélula quadrangular. Compr.: 30,8-33,4 $\mu \mathrm{m}$, larg.: 30-31 $\mu \mathrm{m}$, istmo: 9-10 $\mu \mathrm{m}$.

Material examinado: BRASIL. Paraná: União da Vitória, Reservatório de Salto do Vau, região intermediária, 2-IV-2002, S.A. Felisberto s.n. (HUM11413).

Staurastrum hantzschii Reinsch, Act. Soc. Senckenberg 6: 129. 1867.

Figuras 60-61

Célula 1,3 vez mais longa que larga, sem incluir os processos; constrição mediana rasa, seno aberto; semicélula elíptica, margens laterais convexas, com processos curtos, denticulados, margens côncavas entre os processos; parede celular lisa; cloroplasto com um pirenóide por semicélula; vista apical de semicélula circular, com nove processos denticulados, margens côncavas entre os processos. Compr.: 30,8-40 $\mu \mathrm{m}$, larg.: 23-30 $\mu \mathrm{m}$ (sem processos), istmo: 12,9-20,6 $\mu \mathrm{m}$, proc.: 7,7-12 $\mu \mathrm{m}$.

Material examinado: BRASIL. ParanÁ: União da Vitória, Reservatório de Salto do Vau, região superior, 2-IV-2002, S.A. Felisberto s.n. (HUM11412); idem, região intermediária, 2-IV-2002, S.A. Felisberto s.n. (HUM11413); idem, região lacustre, 2-IV-2002, S.A. Felisberto s.n. (HUM11414); idem, região superior, 6-IX-2002, S.A. Felisberto s.n. (HUM11415).

Staurastrum margaritaceum (Ehrenberg) Ralfs, Brit.

Desm.: 134. 1848 = Pentasterias margaritacea Ehrenberg, Infus.: 144. 1838.

Figuras 62-64

Célula tão longa quanto larga ou 1,1-1,3 vez mais larga que longa, sem incluir os processos; constrição mediana profunda, seno aberto; semicélula obtrapeziforme a transversalmente elíptica, 6 processos robustos, truncados, com extremidades lisas ou 3-denticuladas, 4-5 grânulos; margens serreadas, margem superior convexa, truncada; parede celular lisa; cloroplasto com um pirenóide por semicélula; vista apical da semicélula hexagonal. Compr.: 26,1$30 \mu \mathrm{m}$, larg.: 33,9 $\mu \mathrm{m}$ (sem processos), istmo: 10,4 $\mu \mathrm{m}$, proc.: $5,7 \mu \mathrm{m}$.

Material examinado: BRASIL. PARANá: União da Vitória, Reservatório de Salto do Vau, região lacustre, 2-IV-2002, S.A. Felisberto s.n. (HUM11414); idem, região intermediária, 6-IX-2002, S.A. Felisberto s.n. (HUM11416).

Staurastrum orbiculare (Ehrenberg) Ralfs, Brit. Desm.: 125. 1848 三Desmidium orbiculare Ehrenberg, Phys. Abh. Akad. Wiss. 1833: 22. 1834.

Figuras 65-66

Célula 1-1,2 vez mais longa que larga; constrição mediana profunda, seno fechado; semicélula semicircular a truncada no ápice; parede celular finamente pontuada; vista apical da semicélula triangular, margens laterais retas, às vezes levemente retusas. Compr.: 31-35,2 $\mu \mathrm{m}$, larg.: 30-31 $\mu \mathrm{m}$, istmo: 9-10,3 $\mu \mathrm{m}$.

Material examinado: BRASIL. PARANÁ: União da Vitória, Reservatório de Salto do Vau, região intermediária, 6-IX-2002, S.A. Felisberto s.n. (HUM11416).

Staurastrum orbiculare (Ehrenberg) Ralfs var. depressum Roy \& Bisset, J. Bot. 24: 237. 1886.

Figura 67

Célula 1,2 vez mais longa que larga; constrição mediana profunda, seno fechado; semicélula semicircular-achatada; parede celular finamente pontuada; ápice e ângulos arredondados; vista apical triangular. Compr.: $30 \mu \mathrm{m}$, larg.: $26 \mu \mathrm{m}$, istmo: $6 \mu \mathrm{m}$.

Material examinado: BRASIL. PARANÁ: União da Vitória, Reservatório de Salto do Vau, região intermediária, 2-IV-2002, S.A. Felisberto s.n. (HUM11413); idem, região lacustre, 2-IV-2002, S.A. Felisberto s.n. (HUM11414).

A variedade depressum difere da variedade típica por apresentar-se achatada longitudinalmente, ápice e ângulos arredondados. 
Staurastrum setigerum Cleve, Monogr. Brit. Desm. 136: 13. 1923.

Figuras 68-69

Célula 1,1-1,2 vez mais longa que larga, sem incluir os espinhos; constrição mediana profunda, seno aberto, istmo em forma de V; semicélula elíptica a oblonga, margens ornadas com espinhos longos, ângulos arredondados; cloroplasto com um pirenóide por semicélula; parede celular lisa; vista apical da semicélula triangular, ângulos arredondados, espinhos longos. Compr.: 38-45 $\mu \mathrm{m}$, larg.: 33-40 $\mu \mathrm{m}$, istmo: 14-16 $\mu \mathrm{m}$, esp.: 7,8-10 $\mu \mathrm{m}$.

Material examinado: BRASIL. PARANÁ: União da Vitória, Reservatório de Salto do Vau, região intermediária, 2-IV-2002, S.A. Felisberto s.n. (HUM11413); idem, região lacustre, 2-IV-2002, S.A. Felisberto s.n. (HUM11414).

Staurastrum trifidum Nordstedt var. inflexum West \& G.S. West, Trans. Linn. Soc. Lond. Bot., sér. 2, 5(6): 258.1896.

Figuras 70-71

Célula 1,1 vez mais larga que longa ou tão longa quanto larga, incluindo os espinhos; constrição mediana profunda, seno aberto; semicélula subcuneiforme, margens laterais convexas, espinhos maiores nas margens laterais, inclinados em direção à semicélula oposta, margem superior convexa; cloroplasto com 1 pirenóide por semicélula; parede celular lisa; vista apical da semicélula triangular, margens levemente côncavas, lobos truncados, com três espinhos. Compr.: 30,8 $\mu \mathrm{m}$, larg.: 33,4 $\mu \mathrm{m}$, istmo: 12,8 $\mu \mathrm{m}$, esp.: 5,2 $\mu \mathrm{m}$.

Material examinado: BRASIL. PARAnÁ: União da Vitória, Reservatório de Salto do Vau, região intermediária, 2-IV-2002, S.A. Felisberto s.n. (HUM11413).

\section{Staurodesmus Teiling}

Chave para os táxons de Staurodesmus do reservatório de Salto do Vau

1. Espinhos divergentes, inseridos no terço superior da semicélula..... S. dejectus var. apiculatus

1. Espinhos convergentes, inseridos no terço mediano da semicélula S. dickiei
Staurodesmus dejectus (Bréb.) Teiling var. apiculatus (Bréb.) Teiling, Ark. Bot. 9:6. 1967.

Figuras 72-73

Célula tão longa quanto larga; constrição mediana profunda, seno aberto, com istmo levemente alongado; semicélula triangular invertida, margens laterais com espinhos retos e divergentes, inseridos no terço superior da semicélula, voltados para cima; cloroplasto com 1 pirenóide por semicélula; parede celular lisa; vista apical da semicélula triangular, margens convexas, espinhos curtos nos lobos. Compr.: $20 \mu \mathrm{m}$, larg.: 20,5 $\mu \mathrm{m}$ (com espinhos), istmo: $6 \mu \mathrm{m}$, esp.: $2 \mu \mathrm{m}$.

Material examinado: BRASIL. PARANÁ: União da Vitória, Reservatório de Salto do Vau, região lacustre, 2-IV-2002, S.A. Felisberto s.n. (HUM11414).

Staurodesmus dickiei (Ralfs) Lillieroth, Acta Limnol. 3: 264.1950 = Staurastrum dickiei Ralfs, Brit. Desm.: 123. 1848.

Figuras 74-76

Célula tão larga quanto longa; constrição mediana profunda, seno aberto, semicélula elíptica, margens laterais divergindo para o ápice, ângulos com espinho curto e convergente, inseridos no terço mediano da semicélula; cloroplasto com um pirenóide por semicélula; parede celular lisa; vista apical da semicélula triangular, margens retusas entre os ângulos, espinho curto. Compr.: $26 \mu \mathrm{m}$, larg.: 26,4 $\mu \mathrm{m}$ (incluindo espinhos), istmo: $7 \mu \mathrm{m}$, esp.: $2 \mu \mathrm{m}$.

Material examinado: BRASIL. PARANÁ: União da Vitória, Reservatório de Salto do Vau, região intermediária, 2-IV-2002, S.A. Felisberto s.n. (HUM11413); região superior, 6-IX-2002, S.A. Felisberto s.n. (HUM11415); idem, região intermediária, 6-IX-2002, S.A. Felisberto s.n. (HUM11416); idem, região lacustre, 6-IX-2002, S.A. Felisberto s.n. (HUM11417).

\section{Agradecimentos}

Aos biólogos e técnicos do Núcleo de Pesquisa em Limnologia, Ictiologia e Aqüicultura (Nupélia). À Companhia Paranaense de Energia (Copel) pelo suporte logístico e ao CNPq pela concessão da bolsa de mestrado para S. A. Felisberto e bolsa de produtividade em pesquisa para L. Rodrigues. 


\section{Literatura citada}

Araújo, A. \& Bicudo, C.E.M. 2006. Criptógamos do Parque Estadual das Fontes do Ipiranga, São Paulo, SP. Algas, 22: Zygnemaphyceae (gêneros Actinotaenium, Cosmarium e Heimansia). Hoehnea 33: 219-237.

Bicudo, C.E.M. 1988. Polymorphism in the Desmid Cosmarium abbreviatum var. minus (Zygnemaphyceae) and its taxonomic implications. Acta Botanica Brasilica 2: $1-6$.

Bicudo, C.E.M. \& Menezes, M. 2006. Gêneros de algas de águas continentais do Brasil (Chave de identificação e descrições). RiMa, São Carlos.

Bicudo, D.C. 1996. Algas epifíticas do Lago das Ninféias, São Paulo, Brasil, 4: Chlorophyceae, Oedogoniophyceae e Zygnemaphyceae. Revista Brasileira de Biologia 56: 345-374.

Brook, J.A. 1981. The Biology of desmids. Blackwell Scientific Publications, Oxford.

Bourrelly, P. 1966. Les algues d'eau douce: 1. Les Algues Vertes. N. Boubée \& Cie, Paris.

Croasdale, H. \& Flint, E.A. 1986. Flora of New Zealand: Freshwater algae, Chlorophyta, Desmids. Government Printer, Wellington.

Felisberto, S.A. \& Rodrigues, L. 2004. Periphytic desmids in Corumbá reservoir, Goiás, Brazil: genus Cosmarium Corda. Brazilian Journal of Biology 64: 141-150.

Förster, K. 1982. Conjugatophyceae: Zygnematales und Desmidiales (excl. Zygnemataceae). In: G. HuberPestalozzi (ed.). Das Phytoplankton des Sübwassers: Systematik und Biologie. Schweizerbart'sche Verlagsbuchhandlung, Stuttgart.

Ehrenberg, C.G. 1843. Mikroskopischen Lebens in Süd und Nord-Amerika. Abhandlungen der preussischen Akademie der Wissenschaften 1841: 1-157.

Franceschini, I.M. 1992. Algues d'eau douce de Porto Alegre, Brésil (lês Diatomophycées exclues). Bibliotheca Phycologica 92:1-81.

McCourt, R.M., Karol, K.G., Bell, J., Helm-Bychowski, K.M., Grajewska, A. Wojciechowski, M.F. \& Hoshaw, R.W. 2000. Phylogeny of the conjugating green algae (Zygnemophyceae) based on $r b c \mathrm{~L}$ sequences. Journal of Phycology 36: 747-758.

Mix, M. 1972. Die Feinstruktur de Zellwände bei Mesotaeniaceae und Gonatozygaceae mit einer vergleichender Betrachtung der Conjugatophyceae und über deren systematischen Wert. Archiv für Mikrobiologie 81: 197-220.

Mix, M. 1973. Die Feinstruktur der Zellwände der Conjugaten und ihre systematische Bedeutung. Beih. Nova Hedwigia 42: 179-194.

Pagioro, T.A., Roberto, M.C., Thomaz, S.M., Pierini, S.A. \& Taka, M. 2005. Zonação longitudinal das variáveis limnológicas abióticas em reservatórios. In: L. Rodrigues, S.M. Thomaz, A.A. Agostinho \& L.C. Gomes (eds.). Biocenoses em reservatórios: padrões espaciais e temporais. RiMa, São Carlos.

Parra, O. \& Bicudo, C.E.M. 1995. Introduccion a la Biologia y sistematica de las algas de aguas continentales. Gráfica Andes, Santiago.

Prescott, G.W., Croasdale, H.T., Vinyard, W.C. \& Bicudo, C.E.M. 1981. A synopsis of North American Desmids. Part II. Desmidiaceae: Placodermae. Section 3. In: G.W. Prescott (ed.). Desmidiales. University of Nebraska Press, Lincoln.

Růžička, J. 1977. Die Desmidiaceen Mitteleuropas. v. 1. E. Schweizerbat`sche Verlagsbuchhandlung, Stuttgart. 